\title{
Putative effects of Cry1Ab to larvae of Adalia bipunctata - reply to Hilbeck et al. (2012)
}

\author{
Jörg Romeis ${ }^{*}$, Fernando Álvarez-Alfageme and Franz Bigler
}

\begin{abstract}
In their recent study, Hilbeck et al. (2012) report that Cry1Ab causes lethal effects on larvae of the ladybird beetle Adalia bipunctata when fed directly to the predator. Such toxic effects were not previously observed in a direct feeding study conducted by us (Álvarez-Alfageme et al. 2011). Because Hilbeck et al. (2012) claim that our study design did not allow us to detect any adverse effects we provide arguments for the value and relevance of our study in this commentary. Furthermore we discuss two additional published studies that have not revealed any direct effects of Cry1 Ab on larvae of A. bipunctata and are not mentioned by Hilbeck et al. (2012). One of the studies was conducted in our laboratory under more realistic exposure conditions (Álvarez-Alfageme et al. 2011). Feeding A. bipunctata larvae with spider mites reared on Bt maize did not reveal any adverse effects on lethal and sublethal parameters of the predator. This was despite the fact that the larvae had ingested high amounts of biologically-active Cry1 Ab protein. Thus, we do not see verified evidence that A. bipunctata larvae are sensitive to Cry1 Ab at realistic worst-case exposure concentrations. This, together with the fact that A. bipunctata will be little exposed to Cry $1 \mathrm{Ab}$ under field conditions, allows us to conclude that the risk of Bt maize to this predator is negligible. Support for this comes from the results of many Bt maize field studies that have not revealed evidence for direct Cry1Ab-effects on non-Lepidoptera species.
\end{abstract}

Keywords: Bt maize, environmental risk assessment, ladybird beetles, MON810, non-target organisms

\section{Background}

In 2009, Schmidt et al. [1] reported that larvae of $A$. bipunctata suffered increased mortality during the first larval stage when ingesting the Cry $1 \mathrm{Ab}$ protein that is expressed in some of today's Bt maize varieties including MON810. This study has been criticized for its design, execution, and data interpretation by several scientists $[2,3]$ and by the Central Commission on Biological Safety that advises the Federal Government of Germany $[4,5]$. Two subsequent studies in which A. bipunctata larvae were directly fed with Cry1 Ab conducted by our group [6] and by Porcar et al. [7] could not confirm this toxic effect. Furthermore we did not detect adverse effects of Bt maize expressing Cry1Ab on larvae of $A$. bipunctata in a higher tier, tri-trophic study using $\mathrm{Bt}$ maize-fed spider mites as prey [6].

In their paper "A controversy re-visited: Is the coccinellid Adalia bipunctata adversely affected by $\mathrm{Bt}$

\footnotetext{
* Correspondence: joerg.romeis@art.admin.ch

Agroscope Reckenholz-Tänikon Research Station ART, Reckenholzstr. 191, Zurich 8046, Switzerland
}

toxins?", Hilbeck et al. [8] confirm the findings from their earlier study [1] but do not convincingly address the critical issues regarding study design and execution. While Hilbeck et al. [8] criticize the design and execution of our direct feeding experiment [6], they do not acknowledge our tri-trophic feeding study and the study by Porcar et al. [7].

In this letter we respond to the main points of criticism by Hilbeck et al. [8] on our direct feeding study and discuss the available data in a wider risk assessment context. The fact that we do not address certain statements and claims made by Hilbeck et al. [8] does not imply that we agree with them.

\section{Discussion}

Direct feeding studies assessing the impact of Cry1 Ab on larvae of Adalia bipunctata

In total, three studies prior to Hilbeck et al. [8] have assessed the effect of Cry1Ab on A. bipunctata larvae using different test protocols.

In the study by Schmidt et al. [1], Cry1 Ab was dissolved in a buffer solution and deposited on eggs of

\section{Springer}


Ephestia kuehniella, which were continuously provided to $A$. bipunctata larvae. The Cry1Ab was applied at three different concentrations $(5,25$, and $50 \mu \mathrm{g} / \mathrm{ml})$. First instar larvae in the Bt treatments showed a significant increase in mortality, but no sublethal effects on development time or weight.

Spraying Bt protein on E. kuehniella eggs with the purpose of exposing $A$. bipunctata larvae has raised concern about whether this method was appropriate considering the feeding mode of this species $[3,6]$. We observed the feeding behavior of young larvae in our study and report that "...visual observations revealed that, when preying on E. kuehniella eggs, both first and second instars of $A$. bipunctata sucked out their contents until they were completely depleted. No larva was observed consuming whole eggs or even parts of the egg shell. [...] In no case did the larvae consume the egg shell." [6]. This mode of feeding of young ladybird larvae is well known (e.g., [9]), and has been confirmed by Hilbeck et al. [8].

As the egg shells themselves are not consumed by young A. bipunctata larvae, the ingestion of Cry1Ab deposited on E. kuehniella eggs is thus nil or very limited. Hilbeck et al. [8] claim that they have confirmed Cry1Ab ingestion by means of Agdia Bt-Cry1Ab/1Ac ImmunoStrips $^{\circledR}$ (Agdia Inc., Elkhart, IN, USA). In their study, larvae were provided with cotton balls moistened with a Cry $1 \mathrm{Ab}$ sucrose solution for $24 \mathrm{~h}$ and then fed Cry1Ab-coated E. kuehniella eggs. We do not find the $\mathrm{Cry} 1 \mathrm{Ab}$ analysis convincing evidence for the ingestion of toxin because the authors do not indicate that larvae were washed prior to the analysis. It is highly probable that the body surface of the larvae has been contaminated with Cry1Ab from contact with the moistened cotton ball and the Cry1Ab-coated E. kuehniella eggs. Even if toxin was ingested, it remains unclear whether the larvae ingested the Cry1Ab by feeding on the Btcoated E. kuehniella eggs or by feeding on the Cry1Ab sucrose solution from the cotton ball, or both. Thus the data presented do not allow one to conclude whether $A$. bipunctata in the original study by Schmidt et al. [1] had ingested the Cry1Ab protein. Moreover, the results from the ImmunoStrips ${ }^{\circledR}$ assay do not provide any information on the amount of Cry1Ab toxin involved, which disallows the comparison with the quantitative ELISA results from our study [6]. As Schmidt et al. [1] did not use a positive control (a substance which is known to be toxic to $A$. bipunctata) it is impossible to affirm that the larvae had ingested Bt toxin at all.

We [6] intentionally used a test protocol that differed from that by Schmidt et al. [1] because: (i) we wanted to use a system that ensures that substantial amounts of Bt protein were ingested, and (ii) the information on the test protocol used by Schmidt et al. [1] was not sufficient to repeat their experiment. While the concentration of the Cry1Ab solutions used to treat the E. kuehniella eggs is provided, the amount of toxin solution actually applied to the eggs is not known. Unfortunately, Hilbeck et al. [8] again do not provide this essential piece of information.

In our study, larvae of $A$. bipunctata were provided exclusively with a sucrose solution containing Cry $1 \mathrm{Ab}$ during the first $24 \mathrm{~h}$ in each of their larval instars. The fact that no prey was provided ensured that the larvae consumed the sucrose solution. During the remaining time of the larval stages they were fed exclusively with untreated E. kuehniella eggs to continue their development (termed exposure/recovery protocol by Hilbeck et al. [8]). Since $A$. bipunctata has four larval instars, the test insects were exposed four times $24 \mathrm{~h}$ each. We recorded lethal (mortality) and sublethal (development time, weight) parameters.

For our experiment, a Cry1Ab concentration of $45 \mu \mathrm{g} /$ $\mathrm{ml}$ was selected. This concentration was 10 -fold higher than that measured in Bt maize-fed spider mites, an occasional prey species under field conditions that is known to contain high amounts of toxin. This increased concentration should provide an additional margin of safety for this toxicological assay and also control for the fact that larvae were not continuously exposed $[10,11]$.

Two positive control treatments were included in the bioassay, i.e., the inorganic toxin potassium arsenate and an insecticidal protein (snowdrop lectin, GNA). Ingestion of both toxins revealed adverse effects on the recorded parameters of the $A$. bipunctata larvae. Thus, these positive control treatments confirmed that the test compounds were ingested and that the test system is able to detect treatment effects. The inclusion of positive control (or reference) treatments is an important factor to consider in ecotoxicological studies [10-12].

Porcar et al. [7] provided the Cry1Ab protein at a concentration of $50 \mu \mathrm{g} / \mathrm{ml}$ mixed into an artificial diet. Adalia bipunctata larvae were continuously fed the Cry1Ab-containing diet for a total of six days. No effect of Cry1Ab-feeding on larval mortality was detected when compared to the untreated control diet. As in our study, a positive control treatment confirmed the ingestion of the test diet.

None of the three studies quantified the actual dose of Cry1Ab that was ingested by the A. bipunctata larvae. Thus a direct comparison of the different studies is difficult. This is particularly the case for the studies by Schmidt et al. [1] and our study [6] because they used very different methods to expose the larvae. Consequently, the comparison of the Cry1Ab concentrations provided to $A$. bipunctata larvae in the two studies $[1,6]$ provided in Figure 1 by Hilbeck et al. [8] has no value. The studies by Porcar et al. [7] and Schmidt et al. [1] are more comparable because they both exposed the larvae 
continuously to the Cry1Ab toxin. In contrast to the result of Schmidt et al. [1], however, Porcar et al. [7] did not record a toxic effect of Cry1Ab that was provided at a comparable concentration.

\section{Relevance of the direct feeding study conducted by Alvarez-Alfageme et al. [6]}

We are confident that our direct feeding bioassay should have detected adverse effects of Cry1Ab on A. bipunctata larvae if present, despite the fact that we did not continuously provide the larvae with Cry1Ab. According to good ecotoxicological practice [10-12], we included two positive control treatments in the bioassay which we knew would cause an effect on the life-table parameters that we estimated. The results from these two positive controls verified that our bioassay set-up was sensitive enough to detect adverse effects.

In respect to the fact that we have only exposed the $A$. bipunctata larvae to Cry1Ab during the first $24 \mathrm{~h}$ of each larval stage, Hilbeck et al. [8] state "When this exposure/recovery protocol was applied to a highly sensitive target insect, Ostrinia nubilalis, the lethal effect was either significantly reduced or disappeared altogether." We do not see, however, how the experiment conducted with $O$. nubilalis larvae provides evidence that our interval-feeding assay could not reveal adverse effects of Cry1Ab for the following four reasons:

i) While the data presented show that 4-day old $O$. nubilalis larvae can recover from one day feeding on $\mathrm{Bt}$ maize, larvae that have fed on Bt toxin sprayed maize plants still showed an increased mortality compared to the control. Thus, Hilbeck et al. [8] did show that it is actually possible to detect a treatment effect after $24 \mathrm{~h}$ exposure despite a subsequent period of recovery. The different responses to the two Bt treatments is most likely due to differences in the amount of Cry1Ab that was ingested by the $O$. nubilalis larvae. Unfortunately, Hilbeck et al. [8] have not quantified the amount of Cry1Ab delivered to the O. nubilalis larvae through $\mathrm{Bt}$ maize or Bt toxin-sprayed maize.

ii) The authors used 4-day old O. nubilalis larvae even though it is known that neonates are much more sensitive to Cry1Ab [13], a fact that is also acknowledged by Hilbeck et al. [8]. Because we used neonate A. bipunctata, it would have been better to work with neonate $O$. nubilalis. We are convinced that neonates would have suffered significant mortality after $24 \mathrm{~h}$ feeding on Bt maize. For example, Huang et al. [13] reported a $>95 \%$ mortality of neonate $O$. nubilalis after 2 day exposure to Bt maize. We thus wonder why Hilbeck et al. [8] have chosen a less sensitive larval stage of $O$. nubilalis for this experiment. iii) Hilbeck et al. [8] should have measured a sublethal endpoint such as larval weight when working with 4-day old O. nubilalis larvae. It is well established for the impact of Cry1Ab on O. nubilalis larva, that growth inhibition data are much more sensitive than mortality data (i.e., $\mathrm{EC}_{50}$ values are about one order of magnitude lower than $\mathrm{LC}_{50}$ values) [14]. Further, it is well established that older larvae suffer less mortality from Cry1Ab compared to neonates, but show sublethal effects such as reduced growth. For example, Huang et al. [13] reported that third instar $O$. nubilalis did not suffer mortality when feeding on a Cry1Ab-containing diet $(0.5 \mu \mathrm{g} / \mathrm{g})$ for a period of 7 days, while their weight gain was significantly reduced by $93 \%$. For $A$. bipunctata, we recorded sublethal parameters such as development time and larval weight [6]. We thus wonder why Hilbeck et al. [8] have chosen to measure only mortality, which is a relatively insensitive endpoint in this case.

iv) The experiment conducted by Hilbeck et al. [8] does not follow the protocol of our interval-feeding experiment. The O. nubilalis larvae were exposed to the Cry1Ab protein for $24 \mathrm{~h}$ only and then allowed to recover. In our direct feeding experiment with $A$. bipunctata, the larvae were exposed to the Cry1Ab-containing sucrose solution during the first $24 \mathrm{~h}$ of each of their larval instars. The test insects were thus exposed four times 24 h each, which contrasts with the one-time 24-h exposure in the Hilbeck et al. [8] study.

\section{Higher tier study to assess the risk of Bt maize expressing Cry1 Ab to Adalia bipunctata}

As a common practice in ecotoxicology and in the nontarget assessment of GM plants [10,15], we designed an experiment in which we exposed $A$. bipunctata larvae to more realistic concentrations of $\mathrm{Bt}$ maize-expressed Cry1Ab using a prey herbivore (the spider mite Tetranychus urticae) as a toxin carrier. This was done to test whether the putative hazard reported by Schmidt et al. [1] can be observed under a more realistic route of exposure. Schmidt et al. [1] themselves suggested such studies: "Initial experiments, like the ones conducted in this study, provide important data on toxicological responses of nontarget organisms to Bt toxins. Nonetheless, they cannot simply be extrapolated to describe the potential ecological impacts of Cry proteins in the field, but have to be complemented with experiments under ecologically more realistic conditions." We are thus surprised that the results from our tri-trophic feeding study are not mentioned by Hilbeck et al. [8].

We fed larvae of $A$. bipunctata continuously with Bt maize-reared spider mites. This herbivore is an acceptable food source for young ladybird larvae. The experiment was thus restricted to the first two larval stages. We regard this as sufficient given the fact that Schmidt 
et al. [1] have only observed toxic effects of Cry1 Ab on the first instar. We recorded lethal (mortality) as well as sublethal (development time, weight) parameters. None of these parameters were affected in A. bipunctata larvae fed with Bt maize-reared prey compared to larvae that had received prey reared on control maize.

Spider mites served as an ideal toxin carrier because they are prey of ladybird larvae and are known to contain very high amounts of Cry protein when compared to other herbivores [6,16-18]. Furthermore, we had shown in a previous sensitive insect bioassay that the Cry1Ab ingested by spider mites is biologically active [19], and the spider mites themselves are not affected when feeding on Cry1 Ab-expressing Bt maize [16]. By using a quantitative ELISA, we demonstrated that ladybird larvae contained 0.7 and $0.5 \mu \mathrm{g}$ Cry $1 \mathrm{Ab} / \mathrm{g}$ fresh weight in the first and second instar, respectively, when fed continuously with Bt maize-reared spider mites. In parallel we also tested spider mites that had fed on another $\mathrm{Bt}$ maize line expressing the Coleoptera-active Cry3Bb1 toxin [6]. There we were able to compare the ELISA values to those from ladybird beetle larvae that were collected in field with the same Bt maize [18]. This comparison revealed that the Cry protein concentration detected in larvae from our laboratory bioassay was between 160- and 330-fold higher than that measured in field-collected larvae [6]. This confirms that our tritrophic feeding assay provides realistic worst-case exposure conditions and adds certainty to the conclusion that A. bipunctata is unlikely to be affected by Bt maize expressing Cry1 Ab under field conditions.

\section{Conclusions}

We reject the statement by Hilbeck et al. [8] that we were not able to detect adverse effects of Cry1Ab on $A$. bipunctata larvae in our direct feeding bioassay due to the fact that we only exposed the larvae to the toxin at certain intervals and not in a continuous way as done by Schmidt et al. [1]. The statement made by Hilbeck et al. [8] is based on a bioassay with $O$. nubilalis that is not convincing because it included (i) 4 day-old and thus less sensitive $O$. nubilalis larvae; (ii) only one dose of $24 \mathrm{~h}$ feeding compared to 4 doses of $24 \mathrm{~h}$ feeding in our study; (iii) only mortality as an endpoint, which is known to be less sensitive than sublethal parameters such as growth inhibition used in our study. Even under those conditions, Hilbeck et al. [8] detected a significant difference between the $\mathrm{Bt}$ sprayed leaves and the control leaves, which demonstrates that the assay is suitable to detect effects if present. In addition, Hilbeck et al. [8] ignore two important studies in which A. bipunctata larvae were continuously exposed to $\mathrm{Cry} 1 \mathrm{Ab}$ without revealing any direct lethal or sublethal effects [6,7].
Furthermore, we showed in our tri-trophic feeding study that Bt maize expressing Cry1Ab does not cause adverse effects to $A$. bipunctata larvae under realistic worst case exposure conditions. This together with the fact that many ladybird species, including A. bipunctata, mainly feed on aphids that are known to contain, at best, trace amounts of Cry protein when feeding on Bt maize [20] leads to the conclusion that Cry1 Ab-expressing Bt maize poses a negligible risk to this predator. This conclusion is supported by a large body of evidence from field studies in different parts of the world showing that Cry1 Ab-expressing Bt maize does not cause harm to ladybird beetles or any other non-Lepidoptera species under field conditions [21-23].

\section{Competing interests}

The authors declare that they have no competing interests.

\section{Acknowledgements}

We thank Michael Meissle, Stefan Rauschen, Richard L. Hellmich and Steven E. Naranjo for comments on an earlier draft of the manuscript.

\section{Authors' contributions}

JR, FAA, and FB jointly wrote the commentary. All authors read and approved the final manuscript.

Received: 21 March 2012 Accepted: 19 May 2012

Published: 19 May 2012

\section{References}

1. Schmidt JEU, Braun CU, Whitehouse LP, Hilbeck A: Effects of activated Bt transgene products ( $\mathrm{Cry} 1 \mathrm{Ab}, \mathrm{Cry} 3 \mathrm{Bb})$ on immature stages of the ladybird Adalia bipunctata in laboratory ecotoxicity testing. Arch Environ Cont Toxicol 2009, 56:221-228.

2. Rauschen S: A case of "pseudo science"? A study claiming effects of the Cry1 Ab protein on larvae of the two-spotted ladybird is reminiscent of the case of the green lacewing. Transgenic Res 2010, 19:13-16.

3. Ricroch A, Bergé JB, Kuntz M: Is the German suspension of MON810 maize cultivation scientifically justified? Transgenic Res 2010, 19:1-12

4. ZKBS: Statement of the ZKBS on the risk assessment of MON810 - New studies on the environmental impact of MON810. Germany: Federal Office of Consumer Protection and Food Safety; 2009:Ref. No. 6788-02-13. http:// www.bvl.bund.de/EN/06_Genetic_Engineering/ZKBS/01_Allg_Stellungnahmen/ 05_plants/zkbs_plants_maize_MON810_2009.pdf?_blob=publicationFile\&v=1.

5. ZKBS: Statement of the Central Commission on Biological Safety (ZKBS) on the latest scientific publications on the risk assessment of maize line MON810. Germany: Federal Office of Consumer Protection and Food Safety; 2011:Az. 6790-02-0013. http://www.bvl.bund.de/EN/06_Genetic_Engineering/ZKBS/ 01_Allg_Stellungnahmen/05_plants/zkbs_plants_maize_MON810_statement_ 2011.pdf?_blob=publicationFile\&v=7.

6. Álvarez-Alfageme F, Bigler F, Romeis J: Laboratory toxicity studies demonstrate no adverse effects of Cry1 Ab and Cry3Bb1 to larvae of Adalia bipunctata (Coleoptera: Coccinellidae): the importance of study design. Transgenic Res 2011, 20:467-479.

7. Porcar M, García-Robles I, Domínguez-Escribà L, Latorre A: Effects of Bacillus thuringiensis $\mathrm{Cry} 1 \mathrm{Ab}$ and $\mathrm{Cry} 3 \mathrm{Aa}$ endotoxins on predatory Coleoptera tested through artificial diet-incorporation bioassay. Bull Ent Res 2010, 100:297-302.

8. Hilbeck A, McMillan JM, Meier M, Humbel A, Schlaepfer-Miller J, Trtikova M: A controversy re-visited: Is the coccinellid Adalia bipunctata adversely affected by Bt toxins? Environ Sci Europe 2012, 24:10.

9. Hodek I, Honěk A: Ecology of Coccinellidae. Dordrecht: Kluwer Academic Publishers; 1996

10. Rose RI (Ed): White paper on tier-based testing for the effects of proteinaceous insecticidal plant-incorporated protectants on non-target invertebrates for regulatory risk assessment. Washington, DC: US Environmental Protection 
Agency; 2007. http://www.epa.gov/pesticides/biopesticides/pips/non-targetarthropods.pdf.

11. Romeis J, Hellmich RL, Candolfi MP, Carstens K, De Schrijver A, Gatehouse AMR, Herman RA, Huesing JE, McLean MA, Raybould A, Shelton AM, Waggoner A: Recommendations for the design of laboratory studies on non-target arthropods for risk assessment of genetically engineered plants. Transgenic Res 2011, 20:1-22.

12. Candolfi MP, Blümel S, Forster R, Bakker FM, Grimm C, Hassan SA, Heimbach U, Mead-Briggs MA, Reber B, Schmuck R, Vogt H: (Eds): Guidelines to evaluate side-effects of plant protection products to non-target arthropods. Gent: IOBC/ WPRS; 2000.

13. Huang F, Leonard BR, Gable RH: Comparative susceptibility of european corn borer, southwestern corn borer, and sugarcane corn borer (Lepidoptera: Crambidae) to Cry1Ab protein in a commercial Bacillus thuringiensis corn hybrid. J Econ Entomol 2006, 99:194-202.

14. Marçon PCRG, Young LJ, Steffey KL, Siegfried BD: Baseline susceptibility of European corn borer (Lepidoptera: Crambidae) to Bacillus thuringiensis toxins. J Econ Entomol 1999, 92:279-285.

15. Romeis J, Bartsch D, Bigler F, Candolfi MP, Gielkens MMC, Hartley SE, Hellmich RL, Huesing JE, Jepson PC, Layton R, Quemada H, Raybould A, Rose RI, Schiemann J, Sears MK, Shelton AM, Sweet J, Vaituzis Z, Wolt JD: Assessment of risk of insect-resistant transgenic crops to nontarget arthropods. Nat Biotechnol 2008, 26:203-208.

16. Dutton A, Klein H, Romeis J, Bigler F: Uptake of Bt-toxin by herbivores feeding on transgenic maize and consequences for the predator Chrysoperla carnea. Ecol Entomol 2002, 27:441-447.

17. Obrist LB, Dutton A, Albajes R, Bigler F: Exposure of arthropod predators to Cry1Ab toxin in Bt maize fields. Ecol Entomol 2006, 31:143-154.

18. Meissle M, Romeis J: The web-building spider Theridion impressum (Araneae: Theridiidae) is not adversely affected by $B t$ maize resistant to corn rootworms. Plant Biotech J 2009, 7:645-656.

19. Obrist L, Dutton A, Romeis J, Bigler F: Biological activity of Cry1 Ab toxin expressed by Bt maize following ingestion by herbivorous arthropods and exposure of the predator Chrysoperla carnea. BioControl 2006, 51:31-48.

20. Romeis J, Meissle M: Non-target risk assessment of Bt crops - Cry protein uptake by aphids. J Appl Entomol 2011, 135:1-6.

21. Romeis J, Meissle M, Bigler F: Transgenic crops expressing Bacillus thuringiensis toxins and biological control. Nat Biotechnol 2006, 24:63-71.

22. Wolfenbarger LL, Naranjo SE, Lundgren JG, Bitzer R, Watrud LS: Bt crop effects on functional guilds of non-target arthropods: a meta-analysis. PLoS One 2008, 3(5):e2118.

23. Rauschen S, Schaarschmidt F, Gathmann A: Occurrence and field densities of Coleoptera in the maize herb layer: implications for environmental risk assessment of genetically modified Bt-maize. Transgenic Res 2010, 19:727-744

doi:10.1186/2190-4715-24-18

Cite this article as: Romeis et al:: Putative effects of Cry1 Ab to larvae of Adalia bipunctata - reply to Hilbeck et al. (2012). Environmental Sciences Europe 2012 24:18.

\section{Submit your manuscript to a SpringerOpen ${ }^{\circ}$ journal and benefit from:}

- Convenient online submission

- Rigorous peer review

- Immediate publication on acceptance

- Open access: articles freely available online

- High visibility within the field

- Retaining the copyright to your article

Submit your next manuscript at $\gg$ springeropen.com 